\title{
The Melting, Crystallization and Fluidity of $\mathrm{SiO}_{2}-\mathrm{B}_{2} \mathrm{O}_{3}-\mathrm{Al}_{2} \mathrm{O}_{3}-\mathrm{TiO}_{2}$ Frit for Enamel Glaze
}

\author{
Ying-Liang TIAN ${ }^{1, a}$, Su-Li ZHANG ${ }^{1, b^{*}}$, Lu ZHANG ${ }^{1, c}$ \\ ${ }^{1}$ Beijing University of Technology, Beijing, 100124, China \\ aboli106@163.com, bzhangsuli1029@163.com, 'c1327977894@qq.com \\ ${ }^{*}$ Corresponding author
}

Keywords: Glass Frit, Crystallization, Fluidity, Whiteness.

\begin{abstract}
The influence of temperature on the crystallization and the melting of the glassy frit was discussed. $\mathrm{SiO}_{2}-\mathrm{B}_{2} \mathrm{O}_{3}-\mathrm{Al}_{2} \mathrm{O}_{3}-\mathrm{TiO}_{2}$ frits were obtained by melting batches at different temperatures, were investigated by DTA and the crystallization energy was calculated. The fluidity of the frits upon heating was estimated based on the sintering images. XRD measurements were applied to identify the crystalline phase of the sintered frits. The results show that the frit has reduced activation energy when the melting temperature is high. However, the melting temperature does not have effects on the transition and crystallization temperatures of the glass frit. Although the frit could crystallize at a low temperature, a much higher temperature has to be used for the sintering of the frit to obtain enamel glaze with a high flatness.
\end{abstract}

\section{Introduction}

Enamel is an inorganic coating on the cast iron or steel surface formed by the firing of a glassy glaze. It has very excellent resistance to corrosion, abrasion, high temperature, electrical conductivity. More profoundly, it increases the resistance to chemical attack of the metallic substrate. In addition, enamel makes the iron or steel based products beautiful. Enamels with high whiteness are the most popular coating used for the decoration of cooking and sanitary products [1]. Sanitary-glazes are also technological materials that play a crucial role in the aesthetic quality and durability of the final ceramic output [2-4].

White enamels are made from glassy frit powders containing opacifiers such as $\mathrm{TiO}_{2}, \mathrm{Sb}_{2} \mathrm{O}_{3}, \mathrm{SnO}_{2}$ and $\mathrm{ZrO}_{2}$. Among these opacifiers, $\mathrm{TiO}_{2}$ is widely used in enamel glaze as white pigment [5], due to its relatively cheap price, strong opacification capability. During the firing of the enamel coating, $\mathrm{TiO}_{2}$ crystallizes, offering the coating white appearance. However, the crystallization of a glassy frit powder increases the viscosity of the melted glass phase, and hinders the fluidity of the enamel coating and consequently results in the reduction of the coating roughness. Therefore, a balance between the crystallization and the melting of the glassy frit should be found.

The properties of glaze depend on a variety of aspects: the effects of raw materials and process conditions on the glaze formation and its performances on one hand and the firing conditions on the other hand [6-10]. Many scholars have conducted research on white glazes. A. Bernasconi et al. [11] prepared two sets of sanitary-ware glazes based on different initial mineralogical phases. They studied the influence of composition on some industrially relevant properties of traditional sanitary-ware glaze. K. Boudeghdegh et al. [12] investigated the effect of the chemical composition (amount of raw materials and accordingly the oxides contents) on the glaze properties (whiteness, flexural strength, etc.) in order to improve the quality of the obtained sanitary ware glaze. R. Pina-Zapardiel et al. [13] propose a new safe method to introduce zirconia nanoparticles in a com-mercial ceramic frit, which increase the mechanical properties, opacity as well as wear resistance of the original crystalline frit. However, the effect of firing conditions on enamel performance remains unclear.

In this work, the influence of temperature on the crystallization and the melting of the glassy frit was studied. We prepared fifteen samples in different three melting temperature and five heating rates to explore the melting, crystallization and fluidity of $\mathrm{SiO}_{2}-\mathrm{B}_{2} \mathrm{O}_{3}-\mathrm{Al}_{2} \mathrm{O}_{3}-\mathrm{TiO}_{2}$ frit for enamel glaze and further the optimal whiteness. 


\section{Experimental}

The frits used for the enamel coating preparation have a composition of $\mathrm{TiO}_{2} 16 \mathrm{wt} \%, \mathrm{SiO}_{2} 44 \mathrm{wt} \%$, $\mathrm{Al}_{2} \mathrm{O}_{3}+\mathrm{B}_{2} \mathrm{O}_{3} 22 \mathrm{wt} \%, \mathrm{Na}_{2} \mathrm{O}+\mathrm{K}_{2} \mathrm{O} 14 \mathrm{wt} \%$. Batches were put in a Pt-Rh crucible and melted in a furnace at $1250^{\circ} \mathrm{C}, 1350^{\circ} \mathrm{C}$ and $1450^{\circ} \mathrm{C}$ for $1 \mathrm{~h}$. The melt was occasionally stirred every $30 \mathrm{~min}$. Then, the melt was poured out and quenched in cold water to get frits. The frits were further dried and ground in an agate mill (RESTCH, RM200, Germany).

Differential thermal analysis was performed on a Henjiu HCT thermal analyzer. To evaluate the activation energy of the crystallization of the frits, the samples were heated with different heating rates (2, 5,7 and $10^{\circ} \mathrm{C} / \mathrm{min}$ ). The activation energy of crystallization was calculated based on the slope of the plots of $\ln \left(\mathrm{Tc}^{2} / \beta\right)$ against $1 / \mathrm{Tc}$ using the formula $(1)$ :

$$
\ln \left(\mathrm{T}_{\mathrm{C}}^{2} / \beta\right)=\mathrm{E} /\left(\mathrm{RT}_{\mathrm{C}}\right)+\mathrm{C}
$$

Which $\mathrm{E}, \mathrm{TC}, \beta$ are the activation energy of crystallization, the crystallization peak temperature and the heating rate. $R$ is the gas constant [14].

The sintering process of the frit powder was recorded using a sintering imaging instrument. Based on both the DTA results and the observation of sintering process, the frit samples were sintered at different temperatures. X-ray diffraction analysis was performed on a Shimadzu $7000 \mathrm{X}$ X-ray diffractometer to identify the crystalline phases in the sintered samples. Whiteness was measured by WSB-1 Whiteness Meter to characterize the whiteness of titanium white glaze.

\section{Results and Discussion}

The DTA curves of the frits melted at different temperatures were shown in Figure 1. Generally, the DTA curve of a glass display a small exothermal peak correspondent to the glass transition point, Tg, and one or more crystallization peaks. There were two general trends of the curves presented in Figure 1. One was that the curves were shifting towards higher temperatures when the heating rate applied in the DTA analysis was from 2 to $10^{\circ} \mathrm{C} / \mathrm{min}$. The second trend was that Tg points were not visible when the heating rate was $2^{\circ} \mathrm{C} / \mathrm{min}$, in contrast, the broad crystallization peak at around $650^{\circ} \mathrm{C}$ became weak when the heating rate is $10^{\circ} \mathrm{C} / \mathrm{min}$. These two trends suggest that the crystallization of the glass frit was influenced by the glass transition and softening [15].

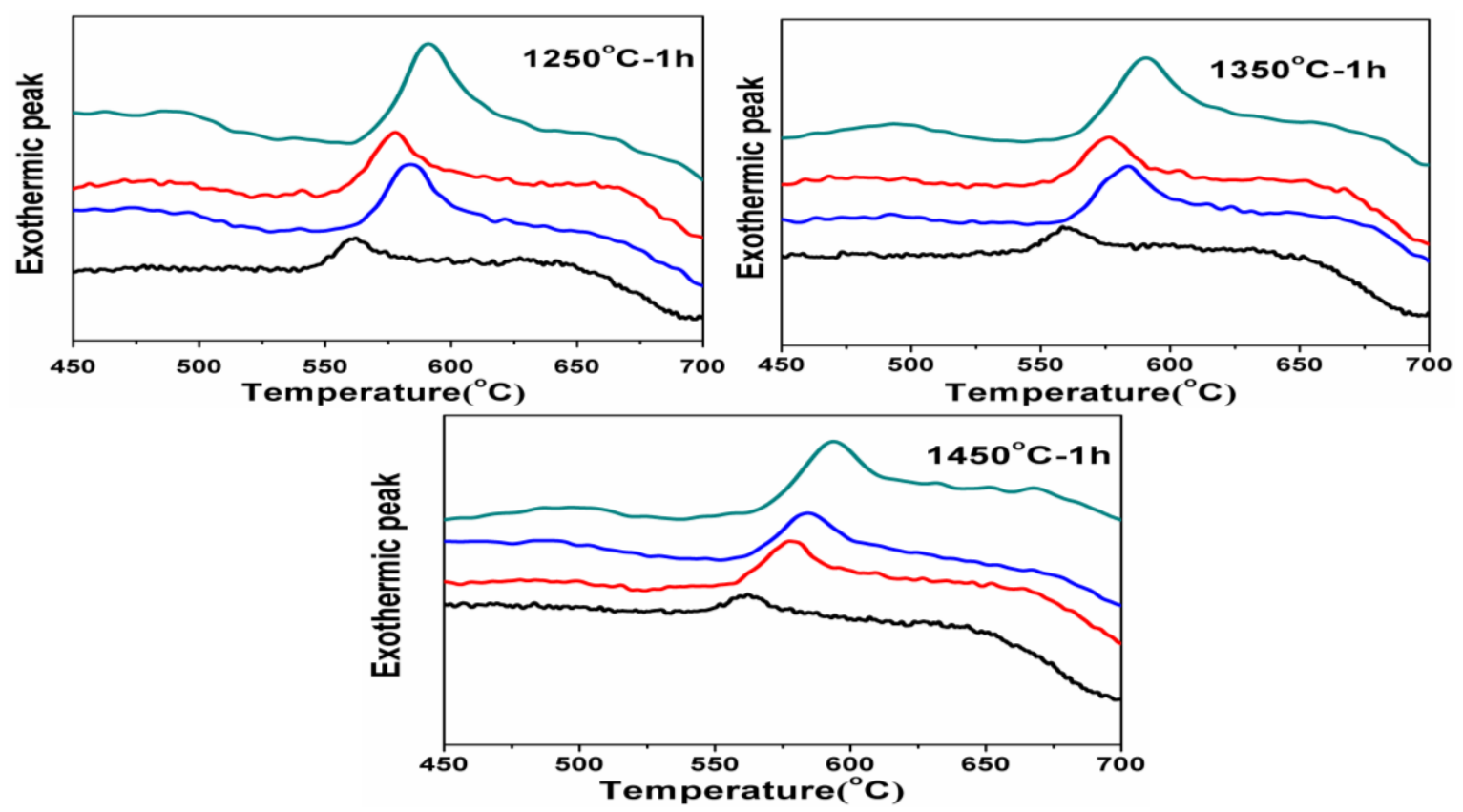

Fig.1 DTA curves of the frits melted at different temperatures (The heating rates of $2,5,7$, and $10^{\circ} \mathrm{C} / \mathrm{min}$ correspondent to the curves from the bottom to the top). 
To compare the glass transition points and the crystallization temperatures, the characteristics data derived from the curves which were obtained with the heating rate of $5^{\circ} \mathrm{C} / \mathrm{min}$ were selected [16]. The data was listed in Table 1. It can be seen that either the glass transition or the crystallization temperature was not affected by the melting temperatures of the frits. Based on slopes of the $\ln \left(\mathrm{Tc}^{2} / \beta\right)$ against $1 / \mathrm{T}_{\mathrm{C}}$ plots shown in Figure 2, the activation energy was calculated and also listed in Table 1. The data indicate that E decreases with the melting temperature. It means that the frit melted at a higher temperature is easy to crystallize.

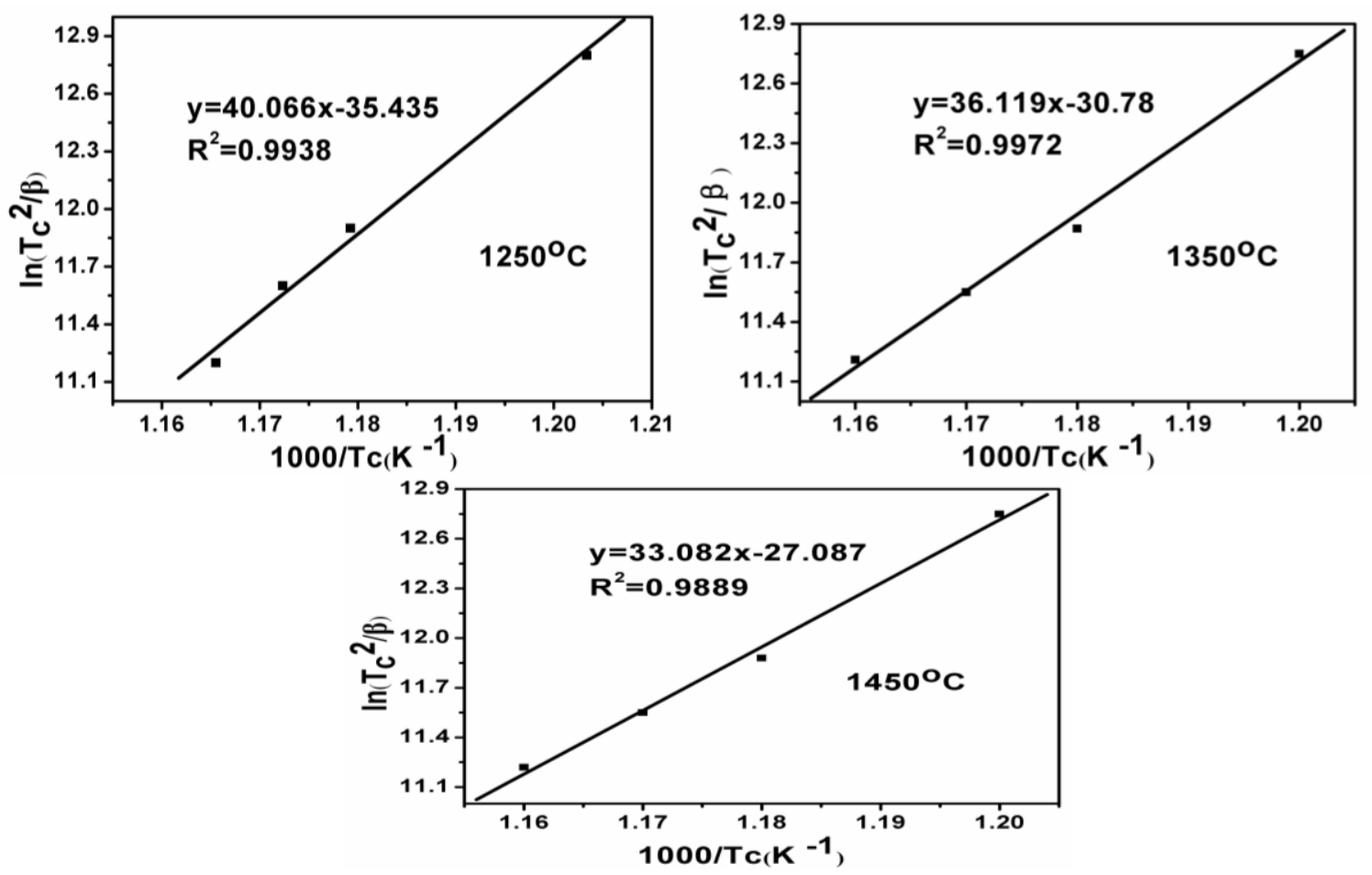

Fig.2 Plots of $\ln \left(\mathrm{Tc}^{2} / \beta\right)$ against $1 / \mathrm{T}_{\mathrm{C}}$ of samples melted at different temperatures.

Tab.1 Transition point ( $\mathrm{Tg})$, crystallization peak temperature $\left(\mathrm{Tc}_{1}, \mathrm{Tc}_{2}\right)$ and the activation energy of crystallization $(\mathrm{E})$ of the glass frits.

\begin{tabular}{lllll}
\hline $\begin{array}{l}\text { Melting } \\
\text { temperature }\left({ }^{\circ} \mathrm{C}\right)\end{array}$ & $\operatorname{Tg}\left({ }^{\circ} \mathrm{C}\right)$ & $\mathrm{Tc}_{1}\left({ }^{\circ} \mathrm{C}\right)$ & $\mathrm{Tc}_{2}\left({ }^{\circ} \mathrm{C}\right)$ & $\mathrm{E}(\mathrm{KJ} / \mathrm{mol})$ \\
\hline 1250 & 500 & 579 & 665 & 333.1 \\
1350 & 498 & 577 & 665 & 300.29 \\
1450 & 497 & 577 & 667 & 275.03 \\
\hline
\end{tabular}

The sintering images of the frit melted at $1450^{\circ} \mathrm{C}$ were depicted in Fig. 3 It can be seen that at the first crystallization peak temperature $\left(\mathrm{Tc}_{1}=577^{\circ} \mathrm{C}\right)$, the compact was densified and liquid phase was obvious, evidenced by the round edges, corners and reduced height of the pressed frit powder body, however, the fluidity was still poor. The fully melting temperature was $641^{\circ} \mathrm{C}$, at which the height of the sintered body was half of the original compact. The height of the sintered body was continuously decreasing from $641^{\circ} \mathrm{C}$ to $692^{\circ} \mathrm{C}$, which was referred to as the flowing temperature. As shown in Table $1,667^{\circ} \mathrm{C}$ was the second crystallization temperature of this sample. Therefore, the results indicate that although the initial crystallization occurred at a low temperature, it is not possible to obtain an enamel glaze with desired flatness. To have a glaze with good quality, the glaze should be sintered at a temperature higher than the flowing temperature. In the meantime, the crystallization is fulfilled. 


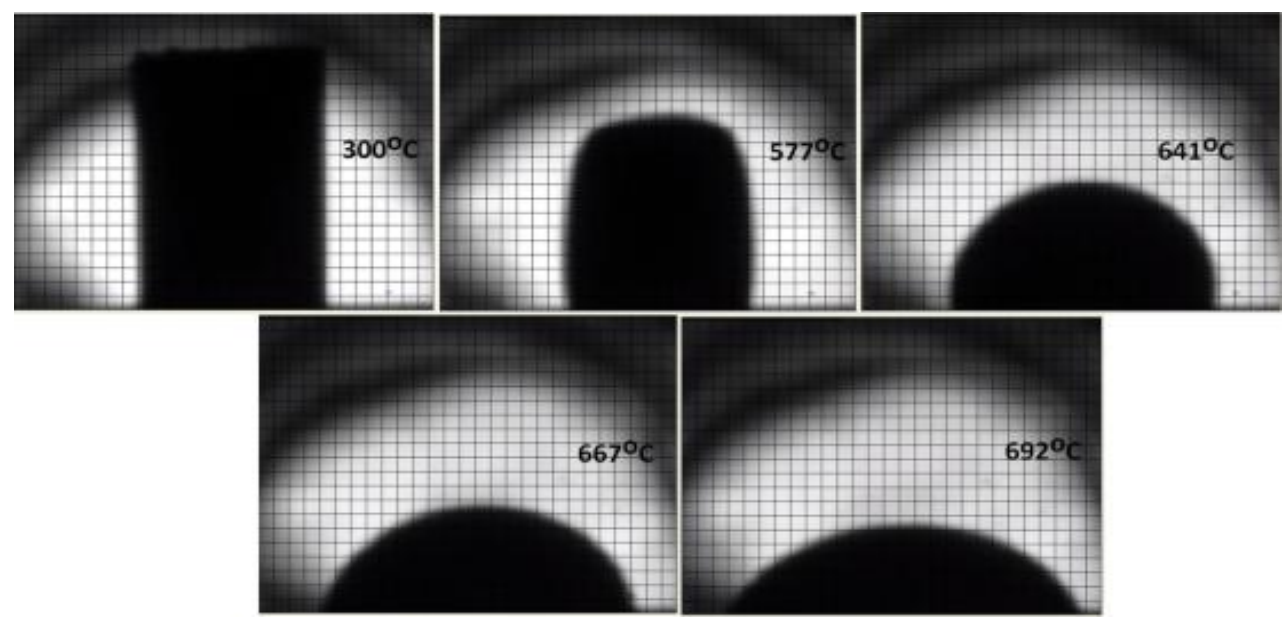

Fig. 3 The sintering images of the frit melted at $1450^{\circ} \mathrm{C}$.

Further examination has been performed on the frit particles sintered at 600,700 and $800^{\circ} \mathrm{C}$. The XRD patterns of the sintered samples were shown in Figure 4. It can be seen that at 600 and $700^{\circ} \mathrm{C}$, the samples were not fully crystallized. The crystalline phase was anatase. Upon the thermal treatment at $800^{\circ} \mathrm{C}$, the sample was well crystallized, giving a crystalline phase of rutile. Combining both the sintering images and XRD results, it can be concluded that upon raising the sintering temperature, the reduced viscosity of the residual glass phase benefits both the flowing and the crystallization of the glass frit [17]. But for white enamel, the crystalline phase obtained under different sintering temperature phases has different whiteness.

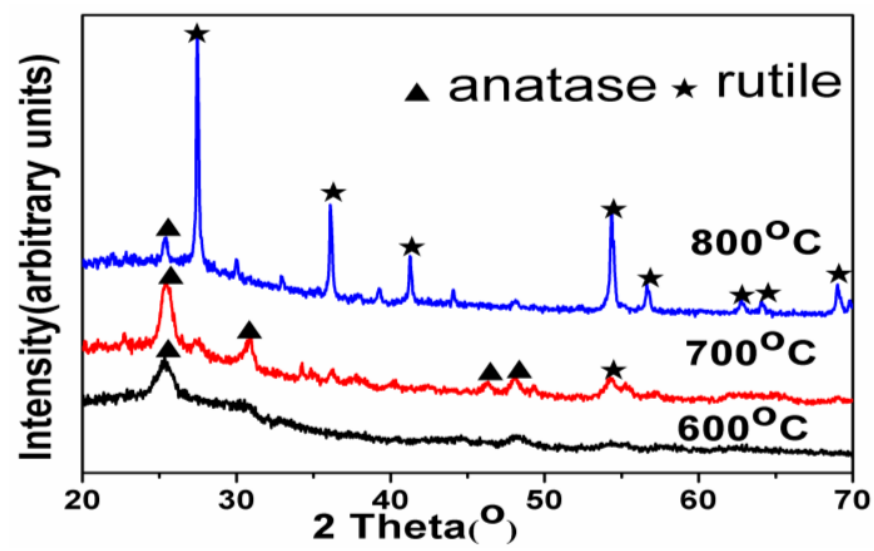

Fig. 4 XRD patterns of the samples sintered at different temperatures

Therefore, the whiteness of the samples sintered at $600,700,800^{\circ} \mathrm{C}$ were measured respectively in results of $76,80,77.3$, the optimal value 80 shows that the optimal sintering temperature is $700^{\circ} \mathrm{C}$. Although, the crystallinity of the sample sintered at $700^{\circ} \mathrm{C}$ was second to that of the sample sintered at $800^{\circ} \mathrm{C}$, the former one showed excellent whiteness, which was because the former one contained more anatase phase. Based on above measurement results, the sintered temperature was controlled at $700^{\circ} \mathrm{C}$ to obtain a better whiteness.

\section{Conclusion}

Titania-containing glass frits could be used for the enamel glaze preparation. In this work the melting, crystallization and fluidity of $\mathrm{SiO}_{2}-\mathrm{B}_{2} \mathrm{O}_{3}-\mathrm{Al}_{2} \mathrm{O}_{3}-\mathrm{TiO}_{2}$ frit for enamel glaze was investigated. It is concluded that: Melting the frit at a high temperature benefits the crystallization of the glass frit. The sintering at a certain high temperature on the one hand facilitates the flowing of the glaze and improves the glass crystallization, on the other hand obtains a good white appearance. Then the enamel sinter at higher temperature, the crystalline phase of rutile increasing, lead to the decease of glaze whiteness. 


\section{References}

[1] F.H. Yu, Y. Liu, Q.K. Cai. Enamel on open innovation and development of new products, J. Chinese enamel. 21 (2000) 7-10.

[2] S. Yan, Q. Liang, H.Y. Duan, Elemental analysis-aided Raman spectroscopic studies on Chinese cloisonné wares and painted enamels from the Imperial Palace, J. Molecular and Biomolecular Spectroscopy. 8(2015) 1386-1425.

[3] L. Hupa, R. Bergman, L. Froberg, Chemical resistance and cleanability of glazed surfaces, J. Surface Science. 584 (2005) 113-118.

[4] L. Froberg, T. Kronberg, L. Hupa, Chemical durability of glazed surfaces, J. Journal of the

[5] European Ceramic Society. 27 (2007) 1811-1816.

[6] L.L. Bragina, G.K. Voronov, Effect of complex of allovaent cations on process in an enamel

[7] melt-low-carbon steel system, J. Glass and Ceramics. 65(2008) 59-62.

[8] L. Froberg, T. Kronberg, L. Hupa, Effect of soaking time on phase composition and topography and surface microstructure in vitro crystalline whiteware glazes, J. Journal of the European Ceramic Society. 29(2009) 2153-2160.

[9] B. Karasu, E. Dolekcekic, B. Ozdemir, Compositional modifications to floor tile glazes opacified with zircon, J. Br Ceram Trans. 100(2001) 81-85.

[10]E. Bou, A. Moreno, A. Escardino, Microstructural study of opaque glazes obtained from frits of the system: $\mathrm{SiO} 2-\mathrm{A} 12 \mathrm{O} 3-\mathrm{B} 2 \mathrm{O} 3-(\mathrm{P} 2 \mathrm{O} 5)-\mathrm{CaO}-\mathrm{K} 2 \mathrm{O}-\mathrm{TiO} 2$, J. Journal of the European Ceramic Society. 27(2007) 1791-1796.

[11]A. Escardino, Kinetic model for crystallization in white ceramic glazes, J. Journal of the American Ceramic Society. 84(2001) 23-28.

[12] W.M. Carty, Matt glaze control through raw materials and process — is it possible? J. Ceramic Engineering and Science Proceedings 24 (2008) 227.

[13]A. Bernasconi, V. Diella, A. Marinoni, Influence of composition on some industrially relevant properties of traditional sanitary-ware glaze, J. Ceramics International. 38(2012) 5859-5870.

[14]K. Boudeghdegh, V. Diella, A. Bernasconi, Composition effects on the whiteness and physical-mechanical properties of traditional sanitary-ware glaze, J. Journal of the European Ce-ramic Society. 35(2015) 3735-3741.

[15] R.P. Zapardiel, A.E. Cubillo, J.F. Bartolomé, High wear resistance white ceramic glaze containing needle like zircon single crystals by the addition of sepiolite $\mathrm{n}-\mathrm{ZrO} 2$, J. Journal of the European Ceramic Society. 33(2013) 3379-3385.

[16]H.E. Kissinger, Variation of peak temperature with heating rate in differential thermal analysis, J. Journal of Research National Bureau Standards. 57 (1956) 217-221.

[17]M.H. Mohamed, S. Srinivasan, K. Chandra, Effect of glass frit chemistry on the physical and electrical properties of thick-film Ag contacts for silicon solar sells, J. Journal of Electronic Materials. 5(2006) 1-7.

[18] Y. Yagen, R.Y. Yerushalmi, M. Gottlieb, Effect of interfaces on the crystallization behavior of PDMS, J. Interface Science. 11 (2003) 199-209.

[19] Y.H Zhang, L. Edwards. Cyclic fatigue crack growth behavior of silicon nitride at 1400 OC, J. Materials Science and Engineering. 1998 141-151. 